\title{
Tumor Necrosis Factor Alpha and Interleukin 6 Productions in Response to Platelet-Activating Factor in Chronic Hepatitis B Virus Infection
}

\author{
A. Cagri Buke ${ }^{a}$ Munir Buke ${ }^{a}$ Imre Erdem Altuglu ${ }^{b}$ Meltem Ciceklioglu ${ }^{c}$ \\ Saniye Kamcioglua Guney Karakartal a Afig Huseyinovd \\ Departments of a Infectious Diseases and Clinical Microbiology, bMicrobiology and Clinical Microbiology, \\ cPublic Health, and dPediatrics, Ege University Medical Faculty, Bornova, Izmir, Turkey
}

\section{Key Words}

Chronic hepatitis B · Platelet-activating factor - Tumor necrosis factor- $\alpha \cdot$ Interleukin- 6 between chronic HBV carriers and naturally immune subjects suggest that TNF- $\alpha$ may be a critical mediator of HBV clearance.

Copyright $\odot 2004$ S. Karger AG, Basel

\begin{abstract}
Objective: The aim of this study was to determine tumor necrosis factor alpha (TNF- $\alpha$ ) and interleukin-6 (IL-6) release in response to platelet-activating factor (PAF) induction in peripheral blood mononuclear cells (PBMCs) from chronic hepatitis B virus (HBV) carriers. Methods: Subjects were grouped into three subgroups. The mean age was $37 \pm 10$ years. Group $A(n=15)$, group $B(n=10)$ and group $C(n=9)$ subjects were HBV serology-negative, had natural immunity after recovery from an acute HBV infection, and were chronic HBV carriers, respectively. Results: Compared with group $A$, PBMCs from naturally immune subjects and chronic HBV carriers produced significantly higher amounts of TNF- $\alpha$ and IL-6 in response to PAF. In chronic HBV carriers, TNF$\alpha(1,633.3 \pm 793.7)$ and IL-6 $(2,533.3 \pm 466.3)$ production was statistically lower than TNF- $\alpha(2,630.0 \pm 727.3)$ and IL-6 (3,870.0 \pm 728.4) obtained from naturally immune subjects to HBV. Conclusion: Differences of TNF- $\alpha$ levels
\end{abstract}

\section{Introduction}

Hepatitis B virus (HBV) infection is one of the most common infectious diseases worldwide. Depending on the interaction between the virus and the host response, there is a wide spectrum of clinical courses of viral hepatitis B [1-3]. Impaired clearance of HBV, which occurs in $10 \%$ of infected patients, results in chronic infection [4, 5]. Lysis of infected hepatocytes by cytotoxic T lymphocytes is crucial for elimination of the HBV. Like interferons, tumor necrosis factor alpha (TNF- $\alpha$ ) is responsible for a number of effects. It is an inhibitor of viral replication [6]. It also induces human leukocyte antigens (HLA) in hepatocytes to activate cytotoxic T lymphocytes. Studies indicate that an altered production of interleukin- 6 (IL-6) may contribute to the changes in cellular immune regulation which occur in patients with acute and chronic viral hepatitis [7, 8]. In recent years, the role of biological-

\begin{tabular}{ll}
\hline KARGER & ( ) 2004 S. Karger AG, Basel \\
Fax +4161306 1234 & \\
$\begin{array}{l}\text { E-Mail karger@karger.ch } \\
\text { www.karger.com }\end{array}$ & $\begin{array}{l}\text { Accessible online at: } \\
\text { www.karger.com/mpp }\end{array}$
\end{tabular}

Assoc. Prof. A. Cagri Buke, MD

Department of Infectious Diseases and Clinical Microbiology

Ege University Medical Faculty

TR-Bornova, Izmir (Turkey)

Tel./Fax +90232 3420871, E-Mail cbuke@med.ege.edu.tr 
ly active substances like platelet-activating factor (PAF) in host response to immune destruction in the liver has been investigated [9-12]. PAF is a potent autocoid mediator, with large pharmacologic and biologic properties. It is responsible for cytokine synthesis and release by peripheral blood mononuclear cells (PBMCs), monocytes, and macrophages. The dose-dependent effect of PAF may induce the release of different cytokines at different levels and affect the host immune response. PAF and cytokines potentiate each others' effects in vivo to modulate immune response [13-16].

In this study, TNF- $\alpha$ and IL-6 levels of PBMCs in response to PAF obtained from $\mathrm{HBV}$-naive subjects, naturally immune subjects to HBV infection and chronic HBV carriers were investigated. The cytokine responses to PAF stimulation were compared with unstimulated results.

\section{Subjects and Methods}

Thirty-four individuals (mean age $37 \pm 10$ years) were divided into three groups according to the HBV serology and the biochemical results. Fifteen healthy individuals ( 9 male, 6 female) with hepatitis B surface antigen (HBs Ag), antibody to hepatitis B core antigen IgG (anti-HBc IgG) and antibody to HBs Ag (anti-HBs)-negative serology and with normal serum alanine transaminase (ALT) and bilirubin levels served as controls (group A); 10 subjects ( 5 male, 5 female) with anti-HBc IgG and anti-HBs seroconversions after acute HBV infection and with normal ALT and bilirubin levels served as postexposure subjects (group B), and 9 cases (4 male, 5 female) with HBs Ag anti-HBc IgG seropositivity but anti-HBs seronegativity after a period of 6 months or more after acute HBV infection, with normal ALT and bilirubin levels and without any histological sign of chronic active hepatitis, chronic persistent hepatitis or cirrhosis served as healthy chronic HBV carriers (group C). Histological examination was only performed in chronic HBV carriers. Patients with alcoholic liver disease, drug-induced hepatitis, autoimmune hepatitis (antinuclear antibody-positive patients), $\alpha_{1}$-antitrypsin deficiency, idiopathic hemochromatosis or infection with known viruses including type A, type $C$, type $D$, type $E$ hepatitis viruses, cytomegalovirus or Epstein-Barr virus and chronic active hepatitis, chronic persistent hepatitis and cirrhosis due to HBV were excluded from the study. HBV serological tests were determined with commercially available enzyme-linked immunosorbent assay (ELISA) kits (Organon Teknika, Holland). HBs Ag, anti-HBc IgG and anti-HBs were investigated as serological markers. ALT and bilirubin levels were observed as biochemical tests.

\section{PBMC Isolation}

PBMCs were separated by a density gradient on Ficoll-Hypaque (Pharmacia, Uppsala, Sweden) from freshly drawn heparinized (preservative-free heparin, Immuno A.G., Vienna, Austria) peripheral venous blood, washed thrice in phosphate-buffered saline and resuspended to $5 \times 10^{6} \mathrm{PBMCs} / \mathrm{ml}$ in RPMI 1640 media (Gibco, Paisley, UK) supplemented with $10 \%$ human $\mathrm{AB}$ serum (Flow Labs., UK),
Table 1. Clinical details of individuals studied

\begin{tabular}{lrllll}
\hline & $\mathrm{n}$ & Age & M/F & ALT, U/l & Bilirubin, mg/dl \\
\hline Control & 15 & $29-45$ & $9 / 6$ & $15 \pm 7$ & $0.8 \pm 0.2$ \\
Post-exposure & 10 & $27-47$ & $5 / 5$ & $24 \pm 9$ & $0.7 \pm 0.3$ \\
Healthy carrier & 9 & $30-43$ & $4 / 5$ & $28 \pm 8$ & $1.0 \pm 0.2$ \\
\hline
\end{tabular}

$\mathrm{M}=$ Male; $\mathrm{F}=$ female

$100 \mathrm{IU}$ penicillin/ml, $100 \mu \mathrm{g}$ streptomycin/ml and $2 \mathrm{mM} \mathrm{L}$-glutamine (Gibco). A hundred milliliters of the cell suspension were pipetted onto cell culture plates (Costar, Cambridge, Mass., USA).

\section{Incubation Procedure}

TNF- $\alpha$ and IL- 6 production by PBMCs was induced by the addition of 1 iM synthetic PAF (PAF C16, Sigma Co., St. Louis, Mo., USA). Cells were incubated for $72 \mathrm{~h}$ at $37^{\circ} \mathrm{C}$ in a humidified atmosphere containing $5 \% \mathrm{CO}_{2}$ (Sanyo, Japan). After the incubation period, supernatant was removed and kept at $-70^{\circ} \mathrm{C}$ until assayed. TNF- $\alpha$ and IL- 6 were analyzed by ELISA (Genzyme Co., USA) method from supernatant. Assays were performed as the kit manufacturers recommended. Results were expressed as picograms/ $5 \times 10^{6}$ cell.

\section{Statistics}

Data are expressed as mean \pm standard deviation. Kruskal-Wallis test was performed to compare TNF- $\alpha$ and IL-6 levels between the groups. Since the results were significant between the groups, Bonferroni-adjusted Mann-Whitney U test was used to compare two groups at a time. To reduce the type 1 error risk, the degree of importance was divided by the number of comparisons and alpha level was found as 0.0167 .

\section{Results}

Details of the subjects studied are summarized in table 1. Stimulation of PBMCs by PAF in chronic HBV carriers and in control cases revealed higher amounts of TNF- $\alpha$ and IL- 6 than those by unstimulated PBMCs. The levels of TNF- $\alpha$ in response to PAF stimulation in naturally immune subjects to $\mathrm{HBV}$ and in cases with chronic HBV carriers were 2,630.0 \pm 727.3 and 1,633.3 \pm 793.7 , respectively, compared to $53.7 \pm 13.2$ in the control group. Similar results were observed for the serum IL-6 level in response to PAF. The stimulated levels of these cytokines in naturally immune subjects and chronic HBV carriers were higher than those in control cases. Low amounts of TNF- $\alpha$ and IL- 6 were secreted by unstimulated PBMCs into the culture supernatant and no differences were observed between the postexposure and healthy carrier groups. As shown in table 2, statistical dif- 
Table 2. TNF- $\alpha$ and IL-6 levels in PBMC culture unstimulated and stimulated with PAF C16

\begin{tabular}{lccccc}
\hline & \multicolumn{2}{l}{ Spontaneous response (unstimulated) } & & \multicolumn{2}{l}{ Stimulated with PAF C16 } \\
\cline { 2 - 3 } & IL-6 & TNF- $\alpha$ & & IL-6 & TNF- $\alpha$ \\
\hline Group A & $15.1 \pm 6.7$ & $14.7 \pm 4.5$ & & $64.8 \pm 11.3$ & $53.7 \pm 13.2$ \\
Group B & $410.0 \pm 74.9$ & $352.0 \pm 64.9$ & & $3,780.0 \pm 728.4$ & $2,630.0 \pm 727.3$ \\
Group C & $353.3 \pm 65.7$ & $276.6 \pm 44.1$ & & $2,533.3 \pm 466.3$ & $1,633.3 \pm 793.7$ \\
\hline \multicolumn{2}{c}{$\mathrm{p}=0.02}$. & & & & \\
\hline
\end{tabular}

ferences were also observed between naturally immune subjects and chronic HBV carriers in response to PAF, the levels of TNF- $\alpha$ and IL-6 being lower in chronic HBV carriers $(\mathrm{p} \leq 0.0167)$.

\section{Discussion}

Differences in the immunological host response are thought to be the major factors that determine the course of hepatitis B infection. Cytokines have an important role in the pathophysiology of acute and chronic viral hepatitis. In the present study, PBMCs from control individuals, subjects with natural immunity after recovery from an acute HBV infection and chronic HBV carriers produced considerable amounts of TNF- $\alpha$ and IL- 6 without stimulation. Possibly, PBMCs were activated in in vitro culture medium and stimulated by a very low level of lipopolysaccharide contamination in human serum. Increased TNF- $\alpha$ and IL- 6 production were seen after PAF stimulation in naturally immune subjects and chronic HBV carriers. This finding indicates that production of both cytokines reflects a response to antigenic stimulation.

PAF is synthesized and secreted from PBMCs, monocytes, and macrophages. Specific PAF receptor is present on the cell membranes of both lymphocytes and monocytes. After binding this receptor, PAF initiates intracellular secondary mRNA synthesis and conducts the signal received via nuclear factor-kappa $B$ to the nucleus and leads to the synthesis of cytokines. The type and amount of cytokines produced may vary according to the dosage and time of exposure to PAF $[13,16]$.

TNF- $\alpha$ and IL-6 have an important role in immunoregulation and inflammation. It has been shown that TNF- $\alpha$ like interferon- $\alpha$ activates HLA in hepatocytes, which induces cytotoxic $\mathrm{T}$ lymphocytes. Lysis of infected hepatocytes by cytotoxic $\mathrm{T}$ lymphocytes is crucial for elimination of the virus. It has been shown that TNF- $\alpha$ synthesis by stimulated PBMCs of patients with chronic hepatitis is increased [17]. In an experimental study, it is shown that a combination of interferon therapy with TNF and IL-2 may improve HBV clearance [18]. An altered production of IL-6 may contribute to the changes in cellular immune regulation that occur in patients with acute and chronic viral hepatitis. Although in patients with acute hepatitis B and C, elevated IL-6 serum levels were observed [19, 20], in another study impaired in vitro production of IL-6 by lipopolysaccharide-stimulated PBMCs from patients with chronic hepatitis B was detected [21]. In this study it is shown that the serum levels of IL-6 in naturally immune subjects to HBV after acute HBV infection and in chronic HBV carriers have been augmented. Elevated and persistent TNF- $\alpha$ and IL-6 levels in PBMCs from naturally immune subjects to HBV after acute infection may be due to residual HBV replication and remnant liver inflammation after recovery from acute $\mathrm{HBV}$ infection [22].

\section{Conclusion}

Our results indicate that PAF can stimulate PBMCs, leading to the release of TNF- $\alpha$ and IL-6. Compared with the control group, PBMCs from naturally immune subjects and chronic HBV carriers produced higher amounts of both TNF- $\alpha$ and IL- 6 in response to PAF. In naturally immune subjects TNF- $\alpha$ and IL- 6 productions were higher than those in chronic HBV carriers. The differences in TNF- $\alpha$ levels between chronic HBV carriers and naturally immune subjects suggest that TNF- $\alpha$ may be a critical mediator of HBV clearance ( $\mathrm{p} \leq 0.0167)$. 


\section{References}

1 Lee MW: Hepatitis B virus infection. N Engl J Med 1997;337:1733-1745.

2 Andus T, Bauer J, Gerok W: Effects of cytokines on the liver. Hepatology 1991;13:364375.

3 Foster GR, Thomas HC: Recent advances in the molecular biology of hepatitis B virus: $\mathrm{Mu}$ tant virus and the host response. Gut 1993;34: $1-3$.

4 Dudley FJ, Fox RA, Sherlock S: Cellular immunity and hepatitis-associated Australia antigen liver disease. Lancet 1972;1:723-726.

5 Eddleston AL, Williams R: Inadequate antibody response to $\mathrm{HbsAg}$ or suppressor T-cell defect in development of active chronic hepatitis. Lancet 1974;2:1543-1545.

6 Wong GH, Goeddel DV: Tumor necrosis factor $\alpha$ and $\beta$ inhibit virus replication and synergize with interferons. Nature 1986;323:819822.

7 Torre D, Zeroli C, Giola M, Ferrario G, Fiori GP, Bonetta G, Tambini R: Serum levels of interleukin-1 alpha, interleukin-1 beta, interleukin-6, and tumor necrosis factor in patients with acute viral hepatitis. Clin Infect Dis 1994; 18:194-198

8 Vingerhoets J, Michielsen P, Vanham G, Bosmans E, Paulij W, Ramon A, Pelckmans P, Kestens L, Leroux-Roels G: HBV-specific lymphoproliferative and cytokine responses in patients with chronic hepatitis B. J Hepatol 1998; 28:8-16.
9 Komatsu Y, Shiratori Y, Hikiba Y, Hashimoto N, Han K, Kawase T, Yoshida H, Okano K, Omata M: Role of platelet-activating factor in pathogenesis of galactosamine-lipopolysaccharide-induced liver injury. Dig Dis Sci 1996;4: 1030-1037.

10 Kasirga E, Coker I, Aydogdu S, Yagci RV, Taneli B, Gousseinov A: Blood levels of leukotrienes (LTC4, D4, E4, B4) and synthesis of leukotriene B4 by peripheral leukocytes in children with acute A and B hepatitis. Turk J Pediatr 1999;4:457-465.

11 Zhou W, McCollum MO, Levine BA, Olson MS: Inflammation and platelet-activating factor production during hepatic ischemia/reperfusion. Hepatology 1992;16:1236-1240.

12 Thomas HC, Pignatelli M, Scully LJ: Viruses and immune reactions in the liver. Scand $\mathbf{J}$ Gastroenterol 1985;114:105-117.

13 Camussi G, Tetta C, Baglioni C: The role of platelet activating factor in inflammation. Clin Immunol Immunopathol 1990;57:331-338.

14 Braquet P, Touqui L, Shen TY, Vargaftig BB: Perspectives in platelet-activating factor research. Pharmacol Rev 1987;39:97-145.

15 Synder F: Chemistry and biochemical aspects of platelet activating factor: A novel class of acetylated ether-linked choline phospholipids. Med Res Rev 1985;5:107-140.
16 Pinckard RN, McManus LN, Hanahan DJ: Chemistry and biology of acetyl glyceryl ether phosphoryl choline (platelet activating factor). Adv Inflamm Res 1982;4:147-150.

17 Yoshioka K, Kakumu S, Arao M, Tsutsumi Y, Inoue M: Tumor necrosis factor alpha production by peripheral blood mononuclear cells of patients with chronic liver disease. Hepatology 1989;10:769-773.

18 Gilles PN, Fey G, Chisari FV: Tumor necrosis factor alpha negatively regulates hepatitis $\mathrm{B}$ virus gene expression in transgenic mice. J Virol 1992;66:3955-3960.

19 Müller C, Zielinski CC: Interleukin-6 production by peripheral blood monocytes in patients with chronic liver disease and acute viral hepatitis. Hepatology 1992;15:372-377.

20 Ren H, Zheng DF, Jia XP: Tumor necrosis factor and interleukin 6 in hepatitis $\mathrm{C}$ virus infection. Chung Hua Nei Ko Tsa Chih 1992;31: 344-346.

21 Kakumu S, Shinagawa T, Ishikawa T, Yoshioka $\mathrm{K}$, Wakita T, Ida N: Interleukin 6 production by peripheral blood mononuclear cells in patients with chronic hepatitis B virus infection and primary biliary cirrhosis. Gastroenterol Jpn 1993;28:18-24.

22 Hodgson PD, Michalac TI: Augmented hepatic interferon gamma expression and T-cell influx characterize acute hepatitis progressing to recovery and residual lifelong virus persistence in experimental adult woodchuck hepatitis virus infection. Hepatology 2001;34:1049-1059. 